\title{
Illiak Kemiğin İntraosseöz Pnömokisti: BT Bulguları
}

\author{
Intraosseous Pneumocyst of The Iliac Bone: CT Findings \\ Mehtap BEKER ACAY
}

Hitit Üniversitesi Çorum Eğitim ve Araştırma Hastanesi, Radyoloji Kliniği, Çorum.

\section{ÖZET}

İntraosseöz gaz birikimi kemiklerde nadir görülen ancak benign bir durum olup genellikle osteodejeneratif değişikliklere ya da travmaya sekonder gelişir. Bazen röntgenogramlarda metastatik lezyonları ya da manyetik rezonans görüntülemede sklerotik lezyonları taklit edebilir. Olgumuzda, iliak kemik içerisinde rastlantısal olarak bulunan pnömokisti tanımladık. Klinisyenler tarafindan çok iyi tanınmayan bu durumun görüntüleme özelliklerinin iyi tanımlanması hastayı biyopsi gibi gereksiz invazif işlemlerden korumak açısından oldukça önemlidir.

Anahtar Kelimeler: Bilgisayarlı Tomografi; iliak Kemik; Manyetik Rezonans Görüntüleme.

\section{ABSTRACT}

Intraosseous gas collection is a benign but rare condition that is generally associated with osteodegenerative changes or trauma. Sometimes it may mimic metastatic lesions in roentgenograms or sclerotic lesions in magnetic resonance imaging. We defined a pneumatocyst of the iliac bone that was incidentally found. Description of characteristic imaging findings of this condition is very important that it is not well known by the clinicians, and that should avoid invasive procedures such as biopsy.

Keywords : Computerized Tomography; lliac bone; Magnetic Resonance Imaging.

\section{OLGU SUNUMU}

Karın ağrısı şikayeti ile hastanemize başvuran olguda, 16 kesitli spiral BT ile $5 \mathrm{~mm}$ kalınlıkta kesitlerle batı BT incelemeleri yapıldı. Tetkiklerinde önemli bir bulguya rastlanmayan hastada, rastlantısal olarak sağ sakroiliak eklem komşuluğunda, iliak kemik içerisinde yaklaşık 15x10 mm boyutlarında, dar geçiş zonuna sahip, lobüle konturlu, hipodens lezyon görüldü. Lezyonun attenüasyon değeri gaz yoğunluğu ile uyumlu olup -569 Hounsfield ünit (HÜ) olarak ölçüldü (şekil 1, şekil 2).

\section{TARTIŞMA}

Kraniofasial kemiklerde normal olarak görülen pnömatizasyon vücudun diğer kemiklerinde genelikle osteomyelit, osteonekroz, travma ya da neoplastik süreçler gibi patolojik durumlarla ilişkili olarak nadiren
Yazışma Adresi / Correspondence: Uzm. Dr. Kadir YÜMLÜ Adres: Demirci Devlet Hastanesi Çocuk Hastalıkları Servisi,Manisa/ Demirci

e-mail: drkyumlu@hotmail.com 


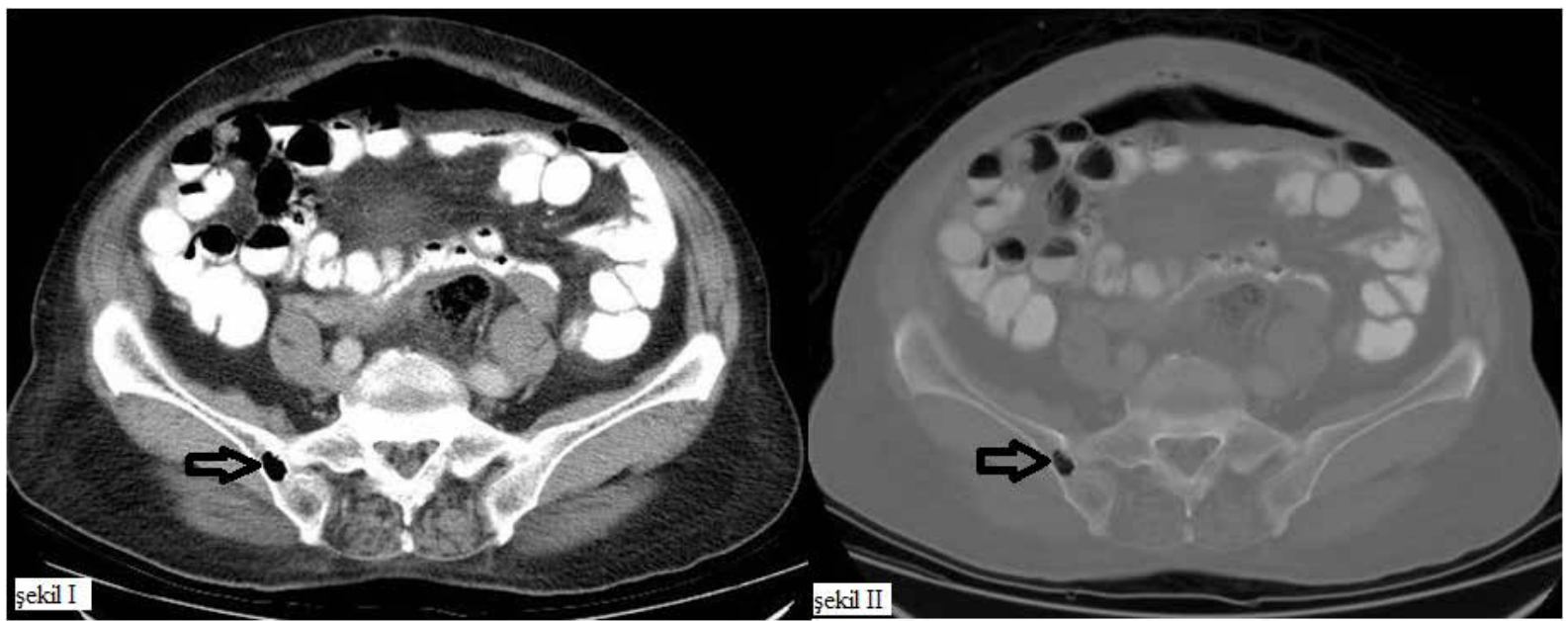

Şekil I, II: Kontrasth batın bilgisayarh tomografi incelemede; yumuşak doku penceresinde (şekil I) ve kemik penceresinde (şekil II), sağ sakroiliak eklem komşuluğunda, iliak kemik içerisinde yaklaşık $15 \times 10 \mathrm{~mm}$ boyutlannda, dar geçiş zonuna sahip, lobüle konturlu, gaz yoğunluğunda (-569 Hounsfield ünit) lezyon (oklar) izlenmektedir.

görülür. Kemiğin benign pnömokistleri, genellikle ekleme komşu (en sık sakroiliak eklem) kemiklerde gaz birikimi ile ortaya çıkan lezyonlardır. Gaz birikiminin subkondral kistik lezyon içerisine hava dolmasıyla oluştuğuna inanılır. Gaz, eklem aralığı ile kemik arasında bağlant meydana gelince vakum fenomeni ile oluşur (1). Kistin sakroiliak ekleme yakın komşuluk göstermes nedeniyle bu görüş olgumuz için geçerli olabilir. Intraosseöz gaz birikimi, gaz oluşturan organizmalar nedeniyle gelişen osteomyelit neticesi de görülebilir. Pnömokist zamanla büyüyebilir ya da kaybolabilir (2). Kist içerisinde hava-sıVı seviyesi gelişebilir. Nadiren, kist granülasyon dokusuna dönüşebilir (3). Illiak intraosseöz pnömokist, ilk kez Ramirez ve arkadaşları tarafindan tanımlanmıştır (4). Pnömokistler, direkt radyogramlarda sklerotik kenarlı, iyi sınırlı radyolusen alan olarak görülürler. Ancak, bazen saptanamayabilir veya barsak gazı ile karışabilirler. Röntgenogramlardaki radyolusen ve osteolitik görünüm intraosseöz pnömokistler, metastaz ya da multipl myelom gibi lezyonları taklit edebilir (5). Manyetik rezonans (MR) incelemelerde, T1 ve T2 ağırlıklı sekanslarda homojen hipointens olarak görünürler. Vertebralardaki MR görünümü ise bazen blastik metastaz, kemik adacığı gibi sklerotik lezyonlarla karıştırılabilir. BT'de -580 ile -950 HÜ arasında düşük atenüasyon değerlerine sahip olmaları ile kesin tanı konur (6). BT inceleme, direkt radyogramdan daha yüksek kontrast rezolüsyonuna sahip olduğundan çok küçük boyutlardaki intraosseöz gaz lezyonlarının saptanmasında daha tanı koydurucudur. Ayrıca, BT'de gaz varlığı ile birlikte kenar sklerozunun görülmesi tanısaldır. Ek olarak, MR artefaktları tanı koymada yarar sağlar. BT ve $M R$ görüntülemede kontrastlanma göstermezler.
Özellikle BT'de gaz yoğunluğunun görülmesinin, diğer görüntüleme yöntemlerine veya biyopsiye gerek bırakmadan doğru tanı konulmasında önemli bir bulgu olduğu vurgulanmaktadır (6). Sonuç olarak, intraosseöz pnömokistler benign ve asemptomatik lezyonlardır. Kemiğin benign pnömokistlerinin tanınması, nadir görülmelerine rağmen, hastaların biyopsi gibi gereksiz invaziv işlemlerden korunması açısından oldukça önemlidir.

\section{KAYNAKLAR}

1. Kamba $\mathrm{M}$, Ohuchi $\mathrm{Y}$, Ogawa $\mathrm{T}$, Ohata $\mathrm{R}$. Intraosseous pneumatocyst of the scapula.

Br J Radiol 2000;73(870):658-60.

2. Wilkinson VH, Carroll T, Hoggard N. contrasting natural histories of thoracic spine pneumatocysts: Resolution versus rapid enlargement. $\mathrm{Br} \mathrm{J}$ Radiol 2011;84(1000):e79-82.

3. Yamamoto $\mathrm{T}$, Yoshiya $\mathrm{S}$, Kurosaka $\mathrm{M}$, et al. natural course of an intraosseous pneumatocyst of the cervical spine. AJR Am J Roentgenol 2002;179(3):667-9.

4. Ramirez H Jr, Blatt ES, Cable HF, et al. Intraosseous pneumatocyst of the Ilium. Findings on radiographs and CT scans. Radiology 1984;150(2):503-5.

5. Cosar M, Eser O, Aslan A, et al. Vertebral body pneumatocyst in the cervical spine and review of the literature. Turk Neurosurg 2008;18(2):197-9.

6. Haithcock JA, Layton KF, Opatowsky MJ. vertebral pneumatocysts: uncommon lesions with pathognomonic Imaging characteristics. Proc (Bayl Univ Med Cent) 2006;19(4):423-4. 